\title{
Constructing and Validating Competence Indicators for Professional Technicians in Fire Safety in Taiwan
}

\author{
Wen-Jye Shyr *, Fan-Yu Shih, Hung-Ming Liau and Po-Wen Liu
}

Citation: Shyr, W.-J.; Shih, F.-Y.; Liau, H.-M.; Liu, P.-W. Constructing and Validating Competence Indicators for Professional Technicians in Fire Safety in Taiwan. Sustainability 2021, 13, 7058. https://doi.org/10.3390/ su13137058

Academic Editors: Kris Law, Yuk-Ming Tang and Jukka Majava

Received: 29 April 2021

Accepted: 21 June 2021

Published: 23 June 2021

Publisher's Note: MDPI stays neutral with regard to jurisdictional claims in published maps and institutional affiliations.

Copyright: (c) 2021 by the authors. Licensee MDPI, Basel, Switzerland. This article is an open access article distributed under the terms and conditions of the Creative Commons Attribution (CC BY) license (https:/ / creativecommons.org/licenses/by/ $4.0 /)$.
Department of Industrial Education and Technology, National Changhua University of Education, No. 1, Jin-De Road, Changhua 500, Taiwan; shihfanyu@gmail.com (F.-Y.S.); liau@sivs.chc.edu.tw (H.-M.L.); lpw1031@yahoo.com.tw (P.-W.L.)

* Correspondence: shyrwj@cc.ncue.edu.tw

\begin{abstract}
This study constructed professional competence indicators for technical personnel in fire safety equipment that can be used to guide curriculum planning of fire-protection-related programs in colleges and universities; training of technical personnel in fire safety equipment in the industry; and the mandatory national examinations for technical personnel in fire protection. To achieve the purpose of this study, document analysis, expert interviews, and the Delphi technique were used to verify that there are three first-level dimension indicators. These three primary indicators were categorized as knowledge, skills, and attitude, with an additional 12 second-level orientation indicators and 61 third-level detailed indicators. Furthermore, in relation to the importance-performance analysis, the falling point distribution of the detailed indicators of technical personnel in fire protection in the four quadrants of the IPA model chart was obtained in order to provide a reference for the industry, government, and academia.
\end{abstract}

Keywords: fire protection equipment; professional technicians; professional competency; indicators; importance-performance analysis (IPA)

\section{Introduction}

In 1995, the National Fire Agency of the Ministry of the Interior was established in Taiwan. Its responsibilities covered fire prevention, disaster relief, and emergency rescue. This demonstrated the increased concern in fire protection by the Taiwanese government. The first national examination for technical personnel in fire safety equipment was held in 1996 to select fire equipment engineers and fire equipment technicians. Ever since specialist fire protection technical personnel have been responsible for fire prevention, the number of fires has been reduced significantly year on year. Therefore, the technical personnel in fire safety equipment involved in fire prevention processes have been effective at reducing fires [1]. Fire safety equipment refers to the devices or tools installed for the purpose of fire prevention, escape, firefighting, and rescue. This is an issue worthy of further research that can assist in constructing professional competence indicators for technical personnel in fire engineering and training technical personnel in fire protection.

Competence is combined of training, skills, experience, knowledge, and behaviors that a person has and their ability to apply them to perform a task safely and effectively. Competence framework provided a common approach to achieving and maintaining the competency of fire safety regulators. It provided an opportunity to demonstrate a commitment to achieving a professional, competent workforce to provide a more consistent standard of regulation [2].

Competence analysis identifies the behaviors required for professionals to perform job-related tasks. Identified behaviors included attitudes, skills, or knowledge of the fundamental characteristics. Specifically, competency refers to the employee performance required to work effectively, especially when adequately playing a role or undertaking a 
task [3]. Thus, competency is not only an aggregation of knowledge, skills, and attitudes but also a dynamic concept of putting theory into practice.

Competence development needs to be focused on learners' lives and current occupational skills. Thus, as competition is a strong factor in learner motivation, government organizations hold various competitions to encourage learners to learn and enrich their knowledge, skills, and attitude [4]. Learners need to be seen as the workforce of the future; therefore, work skills preparation is an important issue in a constantly changing international world [5]. Under the influence of globalization, educational and training institutions now need to consider which skills learners will require and which age to ensure skill development is appropriate for entering the workforce [6].

This study aimed to construct professional competence indicators for technical personnel in fire protection. The two main purposes of this study were as follows: (1) to construct the contents of professional competence indicators for technical personnel in fire safety equipment and (2) to analyze and verify the importance and performance of professional competence indicators for technical personnel in fire safety equipment. The following research questions are raised in this study:

(1) What are the contents of professional competence indicators for technical personnel in fire safety equipment?

(2) What is the importance and performance analysis (IPA) of professional competence indicators for technical personnel in fire safety equipment?

\section{Literature Review}

\subsection{Competence Analysis}

An analysis of competence is meant to identify the factors required to perform jobrelated tasks, including characteristics, skills, and knowledge. Specifically, competence refers to the actions required to play a given role or undertake a given task. Competence is also a dynamic concept involving the practical implementation of theory. The analysis of competence evaluates the ability to achieve a desired outcome in a given situation [7]. To meet the needs for professional competence indicators for technical personnel in fire safety equipment, educators determine the indicators and standards necessary to measure competencies.

Competence has been used to assess training and recruitment techniques as well as the performance of management and employees. Educational professionals use competency in staff development, recruitment, and the design of curriculum [8]. Master [9] described competencies as the activities expected of professionals. Competence model for effective training in these judgments to a set of standards was defined.

In order to construct professional competence indicators for technical personnel in fire safety equipment effectively, what needs to be done first is to analyze the content of the competency so that the indicators concerning measuring competencies can be determined.

\subsection{Technical Personnel of Professional Competence}

Technical personnel of professional competence [10] defined in Article 2 of "Professionals and Technologists Examinations Act" of Taiwan are those who have obtained special academic or technical skills through modern education or training, have engaged in business closely related to public interest or people's right to life, health, and property, and have been awarded the relevant certificates after passing the required examination. Technical personnel in this study refer to "professional fire protection engineers" who design, supervise, install, and maintain fire safety equipment.

Professional competence refers to the valuable actions taken by an individual in terms of cognition, skills, and attitudes in order to complete a task when engaging in professional work [11]. It measures the specialized knowledge, skills, and attitude in the industry to successfully play a specific role in a specific profession and to meet the expectations of the organization or the department [12]. Professional competence in this study refers to the experience and qualifications that fire equipment engineers must have obtained. 


\subsection{Indicators}

Indicators refer to the required specific behavioral performance such as value, idea, action, and integration and can be considered as a guide through which the quality or quantity of things can be understood and measured. Therefore, there are quantitative and qualitative definitions for indicators that are a statistical measurement that reflects important aspects of subjects that are of interest to researchers. In terms of qualitative definition, Spee and Bormans [13] argued that indicators are a signal or guide to show the performance of a system. Indicators in this study refer to professional competence indicators for technical personnel in fire safety equipment.

Shyr et al. [14] identified a number of indicators that are essential for measuring the learning effects on students involved in artificial intelligence (AI)-based robot design. Their data collected from the questionnaires were analyzed using $\mathrm{Z}$ values from the KolmogorovSmirnov test. Employability refers to producing capable graduates, which affects all aspects of a student's university or college life, including the ability to deliver effective academic programs. Patacsil et al. [15] proposed the importance of soft and hard skills as perceived by engineering students and industrial partners and analyzed the skill gap between them. They provided a better picture of soft and hard skills that the industry needs and future graduates are expected to perform. Marrelli et al. [16] presented a step-by-step process for developing a competency model. There is an emerging trend within healthcare to introduce competency-based approaches in the training, assessment, and development of the workforce. This modeling process is drawn from advanced work on competencies in the industry. Gayeski et al. [17] presented computer-aided approaches to competency analysis and provided examples of their use, including a detailed case study analyzing curricula and skills for professionals who provide benefit and work incentive planning and assistance to persons with disabilities.

\section{Methodology}

This study adopted document analysis to develop the first-level professional competence indicators and to complete the preliminary structure of the second-level professional competence indicators.

\subsection{Participants}

\subsubsection{Expert Interviews}

This qualitative research method includes one-on-one interviews and group interviews to obtain information from the other party. Interviews are used in two ways. One is the main method of data collection, and the other is used with participant observation, document analysis, or other techniques. Expert interviews were used in this study to develop the second-level professional competence indicators and to complete the preliminary structure of the third-level professional competence indicators.

Experienced licensed professional fire protection engineers were invited for the interviews. Five fire equipment engineers with more than 20 years of experience were invited for the in-depth interviews. After the opinions obtained from the interview were categorized and concluded, the preliminary structures of the second-level (orientation indicators) and third-level (detailed indicators) competence indicators were developed.

\subsubsection{Delphi Technique Experts}

Experts and scholars were invited to carry out several rounds of questionnaire surveys through brainstorming anonymously until reaching consensus. It was a group decision process that effectively enables all individuals in a group to deal with a complex problem [18]. Researchers from many countries had predicted future developments of business, transportation, and education through the Delphi technique [19]. It was used in this study to construct professional competence indicators for technical personnel in fire safety equipment.

There can be about five to ten members if a heterogeneous Delphi panel is used. If there are more than ten persons in a Delphi panel, the group error can be minimized, and 
group credibility can be maximized [20]. Experts and scholars in industrial, governmental, and academic circles were taken as the research subjects in this study. Five experts from the industry, five experts from the government, and five scholars from the academia were invited. A total of 15 experts and scholars were invited to form a Delphi Panel to participate in this study.

\subsubsection{Importance-Performance Analysis (IPA) Experts}

IPA was first proposed by Martilla and Jamesy [21], who created a two-dimensional matrix diagram that displayed the average scores of motorcycle products in relation to their importance and performance. In the matrix, the axis scale and positions in quadrants can be set at will. The key point was the relative positions of different points in the matrix, and the correlation between their importance and performance was analyzed. It was used in this study to analyze the correlation between importance and performance of professional competence of technical personnel in fire safety equipment.

Licensed fire protection engineers from various fire protection engineers' associations were taken as the research subjects in this study. IPA was carried out for professional competence indicators. Currently, in Taiwan, many fire equipment engineers have joined various associations, including 180 members of Taipei Fire Protection Engineers Association; 120 members of New Taipei City Fire Protection Engineers Association; 33 members of Taoyuan City Fire Protection Engineers Association; 30 members of Hsinchu County Fire Protection Engineers Association; 130 members of Taichung City Fire Protection Engineers Association; 42 members of Tainan City Fire Protection Engineers Association; and 63 members of Kaohsiung City Fire Protection Engineers Association. In terms of sample size, Gay [22] argued that in descriptive research, sample size should account for at least $10 \%$ of the population, and in the case of small population, the minimum sample size should be $20 \%$ of the population. In addition, in correlational studies, the sample size should be at least 30 people. Hence, in this study, more than $20 \%$ of licensed fire protection engineers from each registered association were planned to be invited as the research subjects, totaling 132 licensed fire protection engineers.

\subsection{Instruments}

Questionnaire used a Likert 5-point scale to determine the importance of all detailed indicators (the first draft) listed by the researchers, which was rated on a 5-point scale, ranging from 5 (important) to 1 (unimportant), as the basis for retention or deletion.

The first instrument was expert interview questionnaire, which adopted the "Questionnaire for expert interview on professional competence indicators for technical personnel in fire safety equipment" integrated and developed through document review and analysis, using a semi-structured questionnaire.

The second instrument was Delphi questionnaire, which adopted the first round of "Delphi survey on professional competence indicators for technical personnel in fire safety equipment" integrated and developed based on expert opinions. A semi-structured questionnaire was used in the first round, and a structured questionnaire was used after the second round.

The third instrument was IPA questionnaire, which used the professional competence indicators for technical personnel in fire safety equipment integrated based on Delphi expert opinions to develop the "IPA survey on professional competence indicators for technical personnel in fire safety equipment". In this questionnaire, the relationship between importance and performance of professional competence indicators for technical personnel in fire protection was mainly investigated by IPA. With importance as the vertical axis and performance as the horizontal axis, the rating of each attribute was marked as the coordinate in the two-dimensional space. With the end point of the grade as the separation point, the space is divided into four quadrants. Quadrant I was the "keep up the good work" zone. Its attribute indicates that the professional competence indicators were considered by the interviewed technical personnel as high importance and performance not 
as high as expected and can be regarded as advantages and can continue to be maintained. Quadrant II was the "concentrate here" zone. Its attribute indicated that the professional competence indicators were considered by the interviewed technical personnel as high importance and performance not as high as expected and can be regarded as the items to be improved in priority. Quadrant III was the "low priority" zone. Its attribute indicated that the professional competence indicators were considered by the interviewed technical personnel as low importance and low performance and can be regarded as the items to be strengthened secondarily. Quadrant IV was the "possible overkill" zone. Its attribute indicated that the professional competence indicators were considered by the interviewed technical personnel as low importance and performance higher than expected and are possible overkill, and it was suggested to save time and effort for the items that need to be strengthened in the second quadrant. The analysis model chart was shown in Figure 1.

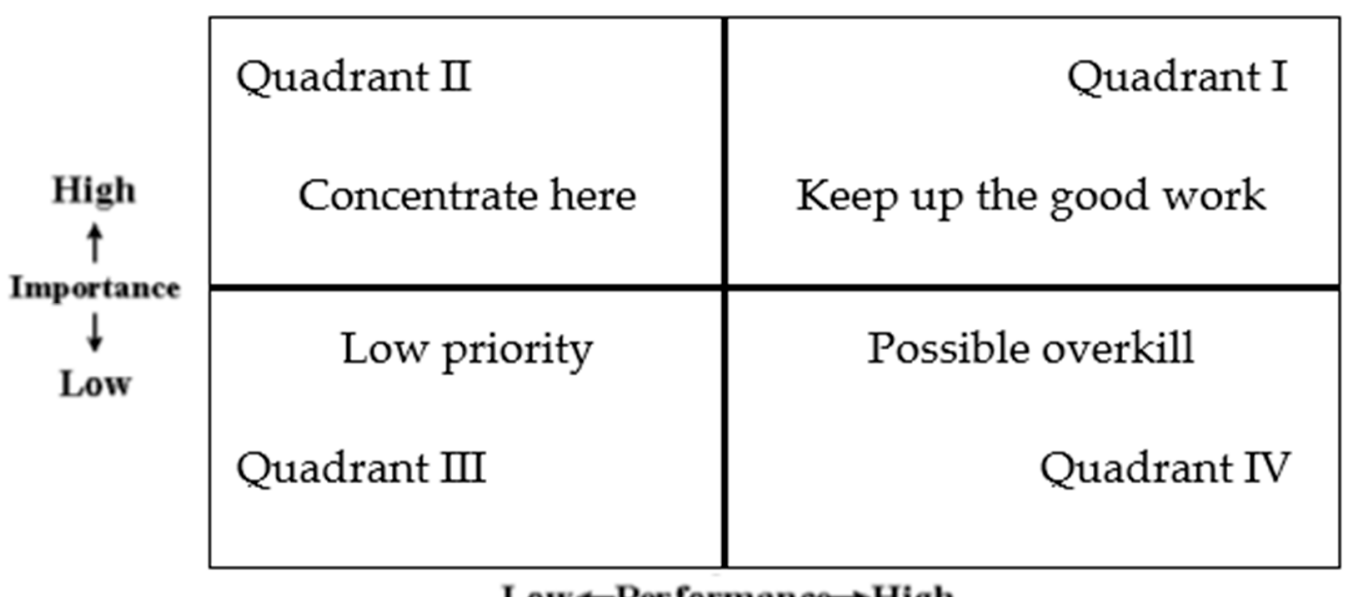

Low $\leftarrow$ Per formance $\rightarrow$ High

Figure 1. IPA model chart.

\subsection{Implementation}

In order to achieve the research purposes, the research was implemented in five stages. In the first stage, "document analysis" was adopted for information collection, conclusion, and integration to develop the first-level professional competence indicators (dimension indicators); in the second stage, based on expert opinions, "expert interviews" were used to categorize and develop the second-level professional competence indicators (orientation indicators) and complete the preliminary structure of the third-level professional competence indicators (detailed indicators); in the third stage, ideas and opinions of experts and scholars were integrated by the Delphi technique to construct the third-level professional competence indicators (detailed indicators); in the fourth stage, the importance and performance of professional competence of technical personnel in fire safety equipment were analyzed by IPA.

\subsection{Data Processing}

Data processing of document analysis: The first-level competence indicators (dimension indicators) of this study were developed by objectively defining, concluding, and organizing the collected literature data, such as information, investigation reports, books, journals, and academic papers, and by identifying and analyzing literature. In addition, other literature data were collected and categorized to provide a reference for expert interview questionnaires and Delphi surveys.

Data processing of expert interviews: One-on-one interviews were conducted to collect interviewees' opinions, viewpoints, and ideas to edit into interview records. According to the interview records, a cross comparison was carried out according to expert opinions to organize appropriate and consistent competence indicators and develop the second-level 
competence indicators (orientation indicators), which later formulated the Delphi survey for this study.

Delphi data processing, verification, and analysis: Qualitative research analysis was based on the opinions and suggestions of the Delphi Panel. The content was analyzed and revised to categorize similar opinions. The "IPA survey on professional competence indicators for technical personnel in fire safety equipment" was applied for the quantitative research analysis. This study referred to Antonio et al. [23] on the criteria for the selection of appropriateness and consistency of this study, as listed below:

\subsubsection{Criteria for Appropriateness Test}

Extremely high appropriateness: the mean $(\mathrm{M})$ is $\geq 4.5$.

High appropriateness: the mean is between 4 and 4.5 .

Low appropriateness: the mean is $<3.5$.

\subsubsection{Criteria for Consistency Test}

High consistency: standard deviation (SD) is $\leq 0.5$.

Moderate consistency: standard deviation is $\leq 1$.

Low consistency: standard deviation is $>1$.

\subsubsection{Kolmogorov-Smirnov One-Sample Test}

In order to be more cautious about the results, Kolmogorov-Smirnov one-sample test was used to evaluate the consistency of opinions amongst respondents (reaching the significant level). Any inconsistent detailed indicator was deleted.

\subsubsection{Importance and Performance Data Processing, Verification, and Analysis}

The IPA was conducted for indicators of licensed fire protection engineers of various fire protection engineers' associations to investigate the importance and performance of indicators. In this study, statistical analyses, such as mean (M) test, standard deviation (SD) test, and paired-samples $t$ test, were used for verification.

\section{Results}

Based on the research methodology, data were analyzed to obtain the results, as discussed below:

\subsection{Expert Interview Process Analysis Results}

Based on the literature review and analysis, the first-level competence indicators (dimension indicators) were constructed for this study, including "knowledge", "skills", and "attitude". Moreover, the second-level competence indicators (orientation indicators) of this study were preliminarily constructed as the basis for the "outline of expert interview", and a semi-structured questionnaire was adopted for the expert interview.

The content and development process of the expert interview are described below.

4.1.1. Establishing "Knowledge Orientation Indicators" and Preliminarily Constructing "Detailed Knowledge Indicators"

After the interview, experts agreed that the "knowledge dimension indicators" of the professional competence of technical personnel in fire safety equipment include four orientation indicators. These were categorized as 1-1"knowledge about fire laws and regulations", 1-2"knowledge about fire safety equipment", 1-3“knowledge about fire theories", and 1-4"auxiliary knowledge about fire engineering", whilst it was suggested that "detailed knowledge indicators" would be utilized to preliminarily construct the second-level orientation indicators and the third-level detailed indicators in the knowledge dimension for this study. 
4.1.2. Establishing "Skill Orientation Indicators" and Preliminarily Constructing "Detailed Skill Indicators"

After the interview, experts agreed that the "skill dimension indicators" of the professional competence of technical personnel in fire safety equipment include four orientation indicators. These were categorized as $2-1$ "fire safety equipment design skills", $2-2$ "fire safety equipment manufacturing supervision skills", 2-3"fire safety equipment installation skills", and 2-4"fire safety equipment maintenance skills", whilst it was suggested that "detailed skill indicators" would be utilized to preliminarily construct the second-level orientation indicators and the third-level detailed indicators in the skill dimension for this study.

\subsubsection{Establishing "Attitude Orientation Indicators" and Preliminarily Constructing "Detailed Attitude Indicators"}

After the interview, experts agreed that the "attitude dimension indicators" of the professional competence of technical personnel in fire safety equipment include four orientation indicators, namely, 3-1"law-abiding attitude", 3-2"honest attitude", 3-3"dedicated attitude", and 3-4"aggressive attitude", and put forward suggestions about "detailed attitude indicators" to preliminarily construct the second-level orientation indicators and the third-level detailed indicators in the attitude dimension for this study.

\subsection{Delphi Survey Analysis Results}

Appropriateness and consistency analysis was conducted on the results of the Delphi survey. The Delphi survey was statistically analyzed by using Kolmogorov-Smirnov onesample test and revised according to the opinions of experts and scholars on addition, deletion, and revision. For example, no significant difference in the test results of all groups indicated consistency. Any inconsistent detailed indicator was deleted from this study.

According to the above statistical analysis and expert opinions in the Delphi survey of this study, this study confirmed 61 indicators for the third layer (see Tables 1-3).

Table 1. The consistency data analysis of the knowledge indicators for K-S test.

\begin{tabular}{|c|c|c|c|}
\hline 1-1 Knowledge about Fire Laws and Regulations & $\mathbf{M}$ & SD & $\begin{array}{l}\text { K-S Test } \\
\text { (Z Value) }\end{array}$ \\
\hline 1-1-1 Knowledge about fire business laws and regulations & 5.00 & 0.000 & Consistency \\
\hline 1-1-2 Knowledge about the building act and building technical code & 4.33 & 0.724 & $1.807 * *$ \\
\hline $1-1-3$ Knowledge about the codes for public safety inspection of buildings & 4.07 & 0.594 & $1.420 *$ \\
\hline 1-1-4 Knowledge about the occupational safety and health act and infra-laws & 3.80 & 0.676 & $1.420 *$ \\
\hline 1-1-5 Knowledge about interior decoration law & 4.07 & 0.458 & $1.078 * *$ \\
\hline \multicolumn{4}{|l|}{ 1-2 Knowledge about fire safety equipment } \\
\hline 1-2-1 Knowledge about fire safety equipment in water systems & 5.00 & 0.000 & Consistency \\
\hline 1-2-2 Knowledge about fire safety equipment in chemical systems & 4.73 & 0.594 & $3.098 * * *$ \\
\hline 1-2-3 Knowledge about fire safety equipment in alarm systems & 5.00 & 0.000 & Consistency \\
\hline 1-2-4 Knowledge about fire escape equipment & 4.87 & 0.352 & $3.357 * * *$ \\
\hline 1-2-5 Knowledge about fire rescue equipment & 4.80 & 0.414 & $3.098 * * *$ \\
\hline \multicolumn{4}{|l|}{ 1-3 Knowledge about fire theories } \\
\hline 1-3-1 Knowledge about fire science & 4.87 & 0.352 & $3.357 * * *$ \\
\hline 1-3-2 Knowledge about fire evacuation & 4.73 & 0.458 & $2.840 * * *$ \\
\hline 1-3-3 Knowledge about fire hazard analysis & 4.60 & 0.632 & $2.582 * * *$ \\
\hline 1-3-4 Knowledge about fire risk assessment & 4.33 & 0.617 & $1.678^{* *}$ \\
\hline 1-3-5 Knowledge about fire rescue tactics & 3.80 & 0.676 & $1.807 * *$ \\
\hline \multicolumn{4}{|l|}{ 1-4 Auxiliary knowledge about fire engineering } \\
\hline 1-4-1 Language knowledge about fire engineering & 4.13 & 0.640 & $1.420 *$ \\
\hline 1-4-2 Physical and chemical knowledge about fire engineering & 4.27 & 0.594 & $1.678 * *$ \\
\hline 1-4-3 Graphic knowledge about fire engineering & 4.73 & 0.458 & $2.840 * * *$ \\
\hline 1-4-4 Knowledge about fire engineering equipment & 4.67 & 0.488 & $2.582 * * *$ \\
\hline 1-4-5 Knowledge of automated control in fire engineering & 4.53 & 0.516 & $2.066^{* * *}$ \\
\hline
\end{tabular}

${ }^{*} p<0.05,{ }^{* *} p<0.01,{ }^{* * *} p<0.001$. 
Table 2. The consistency data analysis of the skill indicators for K-S test.

\begin{tabular}{|c|c|c|c|}
\hline 2-1 Fire Safety Equipment Design Skills & $\mathbf{M}$ & SD & $\begin{array}{l}\text { K-S Test } \\
\text { (Z Value) }\end{array}$ \\
\hline 2-1-1 Computer graphics and engineering calculation software application skills & 4.27 & 0.704 & $1.549 *$ \\
\hline 2-1-2 Integrated design skills of electromechanical systems and fire protection systems & 4.53 & 0.516 & $2.066^{* * *}$ \\
\hline 2-1-3 Integrated design skills of information systems and fire protection systems & 4.33 & 0.488 & $2.582 * * *$ \\
\hline 2-1-4 Integrated design skills of building facilities and fire protection systems & 4.80 & 0.414 & $3.098 * * *$ \\
\hline 2-1-5 Fire simulation software application and performance-based design skills & 4.07 & 0.884 & $1.807 * *$ \\
\hline \multicolumn{4}{|l|}{ 2-2 Fire safety equipment manufacturing supervision skills } \\
\hline 2-2-1 Making and integration skills of manufacturing supervision file data charts & 4.47 & 0.516 & $2.066^{* * *}$ \\
\hline 2-2-2 Fire safety equipment design drawings reading skills & 4.73 & 0.458 & $2.840 * * *$ \\
\hline 2-2-3 Integrated coordination and analysis skills of various kinds of pipelines & 4.73 & 0.458 & $2.840 * * *$ \\
\hline 2-2-4 Integrated coordination and analysis skills of various kinds of lines & 4.67 & 0.488 & $2.852 * * *$ \\
\hline 2-2-5 Inspection and verification skills of various kinds of fire safety equipment & 4.93 & 0.258 & $3.615 * * *$ \\
\hline 2-2-6 Skills of quality control personnel & 4.20 & 0.561 & $1.678^{* *}$ \\
\hline \multicolumn{4}{|l|}{ 2-3 Fire safety equipment installation skills } \\
\hline 2-3-1 Installation and testing of fire pipelines and control panels & 4.93 & 0.258 & $3.615^{* * *}$ \\
\hline 2-3-2 Installation and testing of fire alarms and smoke extraction equipment & 4.93 & 0.258 & $3.615^{* * *}$ \\
\hline 2-3-3 Installation and testing of escape tools and devices & 4.60 & 0.737 & $2.840^{* * *}$ \\
\hline 2-3-4 Fire pump unit installation and test skills & 4.87 & 0.352 & $3.357 * * *$ \\
\hline 2-3-5 Emergency power generator installation and test skills & 4.73 & 0.458 & $2.840^{* * *}$ \\
\hline \multicolumn{4}{|l|}{ 2-4 Fire safety equipment maintenance skills } \\
\hline 2-4-1Maintenance equipment operation, test and determination skills & 4.80 & 0.414 & $3.098 * * *$ \\
\hline 2-4-2 Operation skills of various kinds of fire safety equipment & 4.87 & 0.352 & $3.357 * * *$ \\
\hline 2-4-3 Testing of various kinds of fire safety equipment & 4.93 & 0.258 & $3.615^{* * *}$ \\
\hline 2-4-4 Maintenance skills of various kinds of fire safety equipment & 4.73 & 0.458 & $2.840 * * *$ \\
\hline 2-4-5 Skills of tabulating submitted file data & 4.53 & 0.516 & $2.066^{* * *}$ \\
\hline
\end{tabular}

$$
{ }^{*} p<0.05,{ }^{* *} p<0.01,{ }^{* * *} p<0.001 .
$$

Table 3. The consistency data analysis of the attitude indicators for $\mathrm{K}-\mathrm{S}$ test.

\begin{tabular}{|c|c|c|c|}
\hline 3-1 Law-Abiding Attitude & $\mathbf{M}$ & SD & $\begin{array}{l}\text { K-S Test } \\
\text { (Z Value) }\end{array}$ \\
\hline 3-1-1 Conduct business without offering or accepting bribes & 5.00 & 0.000 & Consistency \\
\hline 3-1-2 Do not disclose any secret known in the course of business & 4.93 & 0.258 & $3.615 * * *$ \\
\hline 3-1-3 Do not promise to others to carry out business in their names & 4.87 & 0.352 & $3.357 * * *$ \\
\hline 3-1-4 Conduct business according to fire protection code and standards & 4.73 & 0.458 & $2.840 * * *$ \\
\hline 3-1-5 Carry out construction according to occupational safety and health regulations & 4.53 & 0.516 & $2.066^{* * *}$ \\
\hline \multicolumn{4}{|l|}{ 3-2 Honest attitude } \\
\hline 3-2-1 Reasonable engineering quotation & 4.60 & 0.507 & $2.324 * * *$ \\
\hline 3-2-2 Ensure engineering quality & 4.87 & 0.352 & $3.357 * * *$ \\
\hline 3-2-3 Accurate test reports & 4.87 & 0.352 & $3.357 * * *$ \\
\hline 3-2-4 Complete construction under contracts & 4.73 & 0.458 & $2.840 * * *$ \\
\hline 3-2-5 Good after-sales services & 4.53 & 0.516 & $2.066^{* * *}$ \\
\hline \multicolumn{4}{|l|}{ 3-3 Dedicated attitude } \\
\hline 3-3-1 Diligent and responsible attitude & 4.80 & 0.414 & $3.098^{* * *}$ \\
\hline 3-3-2 Attitude of good communication & 4.80 & 0.414 & $3.098 * * *$ \\
\hline 3-3-3 Attitude of teamwork & 4.73 & 0.458 & $2.840 * * *$ \\
\hline 3-3-4 Attitude of crisis management & 4.87 & 0.352 & $3.357 * * *$ \\
\hline 3-3-5 Attitude of the fact that tasks must be achieved & 4.60 & 0.507 & $2.324 * * *$ \\
\hline \multicolumn{4}{|l|}{ 3-4 Aggressive attitude } \\
\hline 3-4-1 Aggressive attitude of technology improvement & 4.87 & 0.352 & $3.357 * * *$ \\
\hline 3-4-2 Diligent attitude of new knowledge absorption & 4.87 & 0.352 & $3.357 * * *$ \\
\hline 3-4-3 Aggressive attitude of research and development innovation & 4.33 & 0.617 & $1.678^{* *}$ \\
\hline 3-4-4 Attitude of engineering quality improvement & 4.67 & 0.488 & $2.582 * * *$ \\
\hline 3-4-5 Aggressive attitude of service quality improvement & 4.67 & 0.488 & $2.582 * * *$ \\
\hline
\end{tabular}

$$
{ }^{* *} p<0.01, * * * 00.001
$$




\subsection{Analysis Results of Importance and Performance Questionnaire Survey}

The importance-performance analysis (IPA) was used to check the competence indicator importance based on the expert assessment and the actual contestant performances. The competence indicator facet mean for the cognitive importance of experts was on the $\mathrm{Y}$ axis, and the indicator facet mean for contestant performance from the expert's point of view was on the $\mathrm{X}$ axis; the drop points for the indicator facets were divided into four quadrants, as shown in Figures 2-4.

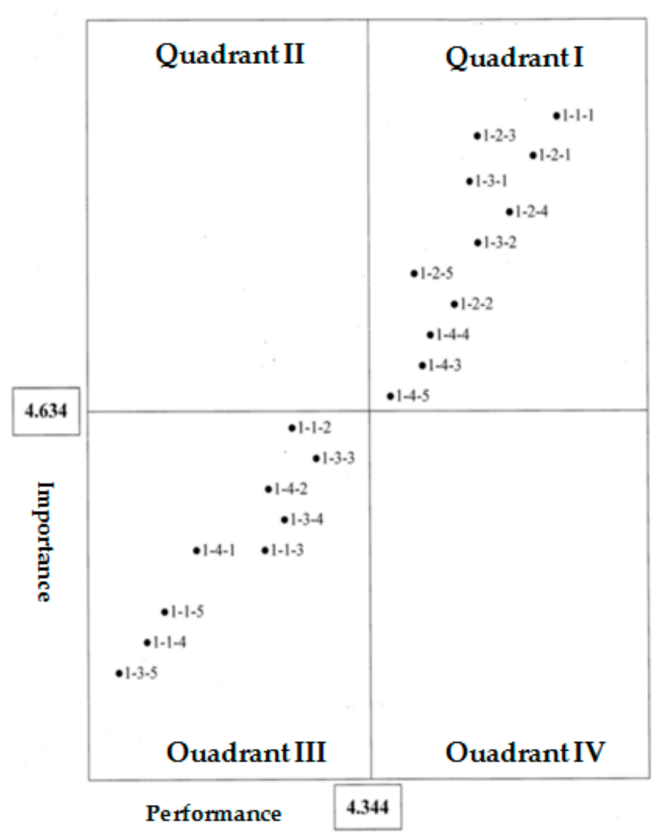

Figure 2. IPA falling points of detailed knowledge indicators.

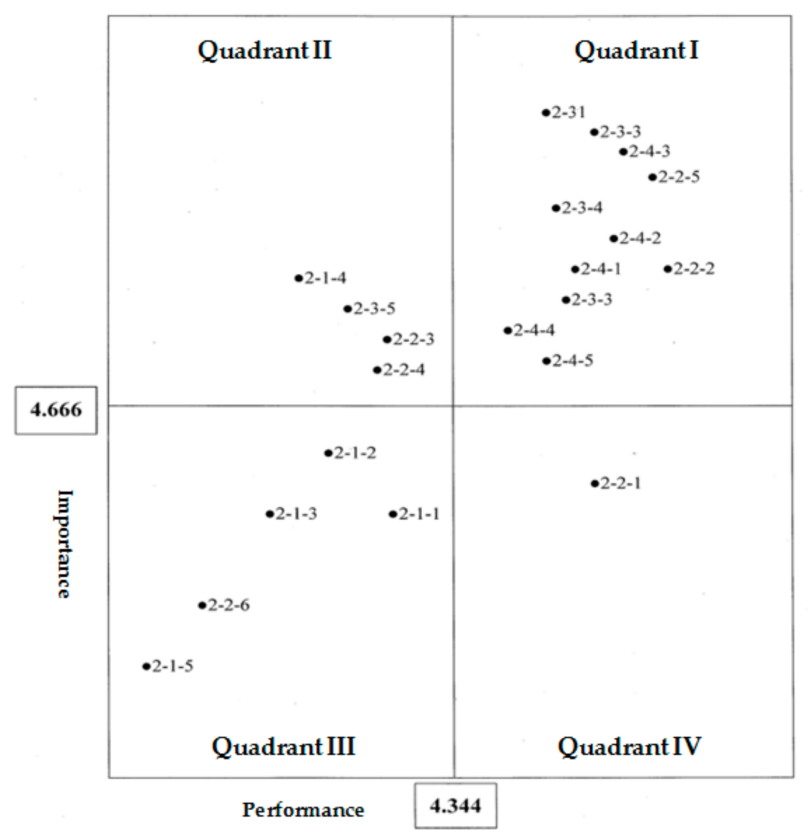

Figure 3. IPA falling points of detailed skill indicators. 


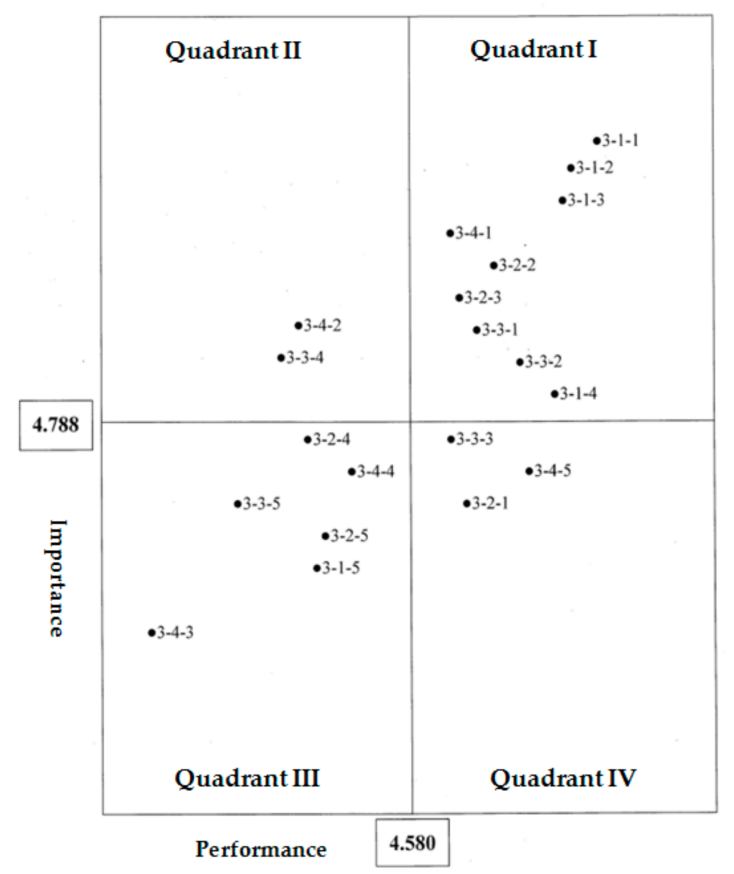

Figure 4. IPA falling points of detailed attitude indicators.

4.3.1. Analysis Results of the Importance and Performance of Knowledge Dimension

The importance and performance of 20 detailed indicators of the knowledge dimension were analyzed statistically using mean (M), standard deviation (SD), and paired-samples $t$ test (see Table 4) for verification. The total mean of importance is 4.634 (Y axis), and the total mean of performance is 4.344 ( $\mathrm{X}$ axis). With the two means as the mid-point, $\mathrm{Y}$ axis and $X$ axis are cut into four quadrants. The IPA falling point distribution of the 20 detailed indicators of the knowledge dimension is as follows. There are 11 detailed indicators in the "keep up the good work" zone (Quadrant I), indicating that the above professional competence indicators are considered by the technical personnel in fire protection of high importance and high performance and can be regarded as advantages and continue to be maintained. There are nine detailed indicators in the "low priority" zone (Quadrant III), indicating that the above professional competence indicators are considered by the technical personnel in fire protection of low importance and low performance and can be regarded as the items to be strengthened secondarily. The falling points of detailed knowledge indicators are shown in Figure 2.

Table 4. The paired-samples $t$ test for knowledge indicators.

\begin{tabular}{ccccc}
\hline & N & M & SD & $\begin{array}{c}\text { Paired-Samples } \\
\boldsymbol{t} \text { Test }\end{array}$ \\
\cline { 1 - 3 } Importance & 20 & 4.634 & 0.321 & $-14.547^{* * *}$ \\
\hline Performance & 20 & 4.344 & 0.329 & \\
\hline${ }_{* * *}^{*} p<0.001$. & & &
\end{tabular}

\subsubsection{Analysis Results of the Importance and Performance of Skill Dimension}

The importance and performance of 21 detailed indicators of the skill dimension were analyzed statistically using mean (M), standard deviation (SD), and paired-samples $t$ test (see Table 5) for verification. The total mean of importance is 4.666 ( $\mathrm{Y}$ axis), and the total mean of performance is 4.344 ( $\mathrm{X}$ axis). With the two means as the mid-point, $\mathrm{Y}$ axis and $\mathrm{X}$ axis are cut into four quadrants. The IPA falling point distribution of the 21 detailed indicators of the skill dimension is as follows. There are 11 detailed indicators in the "keep up the good work" zone (Quadrant I), indicating that the above professional competence indicators are considered by 
the technical personnel in fire protection of high importance and high performance and can be regarded as advantages and continue to be maintained. There are four detailed indicators in the "concentrate here" zone (Quadrant II), indicating that the above professional competence indicators are considered by the technical personnel in fire protection of high importance and performance not as high as expected and can be regarded as the items to be improved in priority. There are five detailed indicators in the "low priority" zone (Quadrant III), indicating that the above professional competence indicators are considered by the technical personnel in fire protection of low importance and low performance and can be regarded as the items to be strengthened secondarily. There is one detailed indicator in the "possible overkill" zone (Quadrant IV), indicating that the above professional competence indicators are considered by the technical personnel in fire protection of low importance and performance higher than expected and can be regarded as overkill, and the efforts can be directed to the items that need to be strengthened. The falling points of detailed skill indicators are shown in Figure 3.

Table 5. The paired-samples $t$ test for skill indicators.

\begin{tabular}{cccccc}
\hline & N & M & SD & $\begin{array}{c}\text { Paired-Samples } \\
t \text { Test }\end{array}$ \\
\cline { 1 - 3 } Importance & 21 & 4.666 & 0.258 & $-8.563^{* * *}$ \\
\cline { 1 - 3 } Performance & 21 & 4.344 & 0.322 & \\
\hline$* * * 0.001$. & & & &
\end{tabular}

\subsubsection{Analysis Results of the Importance and Performance of Attitude Dimension}

The importance and performance of 20 detailed indicators of the attitude dimension were analyzed statistically using mean (M), standard deviation (SD), and paired-samples $t$ test (see Table 6) for verification. The total mean of importance is 4.788 ( $\mathrm{Y}$ axis), and the total mean of performance is 4.580 ( $\mathrm{X}$ axis). With the two means as the mid-point, $\mathrm{Y}$ axis and $X$ axis are cut into four quadrants. The IPA falling point distribution of the 20 detailed indicators of the attitude dimension is as follows. There are nine detailed indicators in the "keep up the good work" zone (Quadrant I), indicating that the above professional competence indicators are considered by the technical personnel in fire protection of high importance and high performance and can be regarded as advantages and continue to be maintained. There are two detailed indicators in the "concentrate here" zone (Quadrant II), indicating that the above professional competence indicators are considered by the technical personnel in fire protection of high importance and performance not as high as expected and can be regarded as the items to be improved in priority. There are six detailed indicators in the "low priority" zone (Quadrant III), indicating that the above professional competence indicators are considered by the technical personnel in fire protection of low importance and low performance and can be regarded as the items to be strengthened secondarily. There are three detailed indicators in the "possible overkill" zone (Quadrant IV), indicating that the above professional competence indicators are considered by the technical personnel in fire protection of low importance and performance higher than expected and can be regarded as overkill, and the efforts can be directed to the items that need to be strengthened. The falling points of detailed attitude indicators are shown in Figure 4.

Table 6. The paired-samples $t$ test for attitude indicators.

\begin{tabular}{ccccc}
\hline & N & M & SD & $\begin{array}{c}\text { Paired-Samples } \\
\boldsymbol{t} \text { Test }\end{array}$ \\
\hline Importance & 20 & 4.788 & 0.151 & $-5.690^{* * *}$ \\
\hline Performance & 20 & 4.580 & 0.250 & \\
\hline${ }^{* * *} p<0.001$. & & & &
\end{tabular}




\section{Discussion}

This study makes three important contributions. First, the results add to the literature by presenting a set of competence indicators for technical personnel in fire safety equipment, and their relative importance and performance were based on empirical data. Second, the competence indicators identified in this study can contribute to the development and improvement of learner support training programs. Third, the findings improve the methodology of determining competency by piloting expert interviews, Delphi technique experts, and IPA experts involving both qualitative and quantitative approaches.

The findings indicate the kinds of professional competencies as well as intrinsic and extrinsic motivations required by institutions to promote efficient training and learning. As indicated in other studies [24,25], comprehensive, ongoing learner support systems are required to help learners. This study demonstrates the value of the three-phase method (expert interviews, Delphi technique experts, and IPA experts) as a systematic and reliable methodology for identifying professional competence indicators for technical personnel in fire safety equipment. Various methods were applied individually and in combination to identify and validate the competencies of various professionals [26]. The proposed method integrates carefully selected expert interviews, Delphi technique experts, and a validation survey using the IPA method. These competencies were then clarified, elaborated on, validated, and classified by experts in the field and experienced researchers.

The implications of the results in this study are discussed as follows:

\subsection{First-Level Professional Competence Indicators (Dimension Indicators)}

By literature review and analysis, after professional competence was defined and organized by scholars at home and abroad, the first-level professional competence indicators (dimension indicators) of this study were determined, including: one knowledge, two skill, and three attitude indicators.

\subsection{Second-Level Professional Competence Indicators (Orientation Indicators)}

After experts were selected for the interview, a cross comparison was carried out according to expert opinions to determine the second-level professional competence indicators (orientation indicators) of this study. There are a total of 12 orientation indicators: four orientation indicators in the knowledge dimension, four orientation indicators in the skill dimension, and four orientation indicators in the attitude dimension.

\subsection{Third-Level Professional Competence Indicators (Detailed Indicators)}

A Delphi panel was selected for the Delphi survey. After data processing, the thirdlevel professional competence indicators (detailed indicators) of this study were finally determined. There were a total of 61 detailed indicators: 20 detailed indicators in the knowledge dimension, 21 detailed indicators in the skill dimension, and 20 detailed indicators in the attitude dimension.

\section{Conclusions}

This study used the Delphi technique method, where the contents of professional competency indicator details for technical personnel in fire safety equipment were built and subsequently divided into three categories, 12 second-level indicators, and 61 detailed indicators. The detailed indicators were then analyzed using the importance-performance analysis (IPA). For experts, the professional field was found to be the most important indicator for the knowledge, skills, and attitude in a specialty area. In terms of contestant performance from the expert point of view, specialty skill performances were seen as the more important ones with the ability to measure performance being the most important in this area. A detailed competency table was constructed, expert academic opinion assessment, which could be a useful reference to verify the abilities during training.

Regarding the contents of competence indicators at all levels, the results in the order of the research implementation are concluded. According to the results, the importance 
and performance analysis of the obtained 61 detailed indicators of professional competence for technical personnel in fire safety equipment were analyzed, as detailed below:

\subsection{Indicators in the "Keep Up the Good Work" Zone (Quadrant I)}

There are 31 detailed indicators in the "keep up the good work" zone, Quadrant $\mathrm{I}$, indicating that the professional competence indicators in this zone are considered by the technical personnel in fire protection of high importance and high performance and can be regarded as advantages and continue to be maintained. The detailed indicators falling in this zone of the IPA model chart are: 11 detailed indicators in the knowledge dimension, 11 detailed indicators in the skill dimension, and 9 detailed indicators in the attitude dimension.

\subsection{Indicators in the "Concentrate Here" Zone (Quadrant II)}

There are six detailed indicators in the "concentrate here" zone, Quadrant II, indicating that the professional competence indicators in this zone are considered by the technical personnel in fire protection of high importance and performance not as high as expected and can be regarded as the items to be improved in priority. The detailed indicators falling in this zone of the IPA model chart are four detailed indicators in the skill dimension.

\subsection{Indicators in the "Low Priority" Zone (Quadrant III)}

There are 20 detailed indicators in the "low priority" zone, Quadrant III, indicating that the professional competence indicators in this zone are considered by the technical personnel in fire protection of low importance and low performance and can be regarded as the items to be strengthened secondarily. The detailed indicators falling in this zone of the IPA model chart are: nine detailed indicators in the knowledge dimension, five detailed indicators in the skill dimension, and six detailed indicators in the attitude dimension.

\subsection{Indicators in the "Possible Overkill" Zone (Quadrant IV)}

There are four detailed indicators in the "possible overkill" zone, Quadrant IV, indicating that the professional competence indicators in this zone are considered by the technical personnel in fire protection of low importance and performance higher than expected and can be regarded as overkill. The efforts can be directed to the items that need to be strengthened. The detailed indicators falling in this zone of the IPA model chart are: one detailed indicator in the skill dimension and three detailed indicators in the attitude dimension.

The competencies identified in this study could serve as a reference for curriculum planning of fire-protection-related teaching programs in colleges and universities, training of technical personnel in fire safety equipment in the industry, and the national examination for technical personnel in fire protection.

It is worth noting that the selection of Taiwan participants who are well-versed in experienced licensed professional fire protection engineers may limit the generalized ability of our findings.

Author Contributions: All authors contributed meaningfully to this study. W.-J.S. and P.-W.L.research topic; H.-M.L. and F.-Y.S.—data acquisition and analysis; W.-J.S. and H.-M.L.-methodology support; W.-J.S., F.-Y.S. and P.-W.L.- original draft preparation; W.-J.S.—writing review and editing. All authors have read and agreed to the published version of the manuscript.

Funding: This research received no external funding.

Institutional Review Board Statement: Not applicable.

Informed Consent Statement: Not applicable.

Data Availability Statement: Not applicable.

Conflicts of Interest: The authors declare no conflict of interest. 


\section{References}

1. Ministry of the Interior. Standard for Installation of Fire Safety Equipment Based on Use and Occupancy. 2018. Available online: https:/ /law.moj.gov.tw /ENG/LawClass /LawSearchContent.aspx?pcode=D0120029\&kw1=firesafetyequipment (accessed on 12 May 2021).

2. National Fire Chiefs Council (NFCC). Competency Framework for Fire Safety Regulators, Ver. 1.0. 2020. Available online: https:// www.nationalfirechiefs.org.uk/write/MediaUploads/NFCC\%20meetings/2020/February/Item11-CompetenceFramework_ 2020.pdf (accessed on 12 May 2021).

3. Shang, C.W.K. Singapore's experiences in developing and implementing competency-based training. In Proceedings of the Conference on Competency-Based Training, Taipei, Taiwan, 19-21 October 2000.

4. Chen, W.L.; Chen, Z.H. The research on selecting contestant indicator of costume design group for national senior secondary school skill competition. Des. Res. 2010, 13, 25-42.

5. Kumpikaitè, V.; Ramírez, A.M.; Ribeiro, H.N.R. Students' skills evaluation: An intercultural study. Procedia Soc. Behav. Sci. 2012, 62, 208-212. [CrossRef]

6. Maryam, E.; Davoud, M.M.; Zahra, G.; Somayeh, B. Effectiveness of life skills training on increasing self-esteem of high school students. Procedia Soc. Behav. Sci. 2011, 30, 1043-1047. [CrossRef]

7. Chao, C.Y.; Liao, W.C.; Chien, F.E.; Huang, Y.L. Construction of a competency analysis model for vocational high schools. World Trans. Eng. Technol. Educ. 2003, 2, 121-124.

8. Russ-Eft, D.; Bober, M.; Teja, I.; Foxon, M.; Koszalka, T. Evaluator Competencies: Standards for the Practice of Evaluation in Organizations; Jossey-Bass: San Francisco, CA, USA, 2008.

9. Master, B. Staffing for success: Linking teacher evaluation and school personnel management in practice. Educ. Eval. Policy Anal. 2014, 36, 207-227. [CrossRef]

10. Ministry of Examination. Professionals and Technologists Examinations Act. 2013. Available online: https://law.moj.gov.tw/ ENG/LawClass/LawAll.aspx?pcode=R0040001 (accessed on 12 April 2021).

11. Chaing, W.Y.; Huang, Y.K. Investigation on professional competence of preschool physical education teachers. Sports Res. Rev. 2004, 72, 165-188.

12. Shyr, W.J.; Chen, C.H.; Wang, Y.X.; Chen, D.F.; Cheng, C.L. Establishing competence indicators to guide teaching automotive coating techniques. Int. J. Eng. Educ. 2021, 37, 185-194.

13. Spee, A.; Bormans, R. Performance indicators in government institutional relations: The conceptual framework. High. Educ. Manag. 1992, 4, 139-155.

14. Shyr, W.J.; Yang, F.C.; Liu, P.W.; Hsieh, Y.M.; You, C.S.; Chen, D.C. Development of assessment indicators for measuring the student learning effects of artificial intelligence based robot design. Comput. Appl. Eng. Educ. 2019, 27, 863-868. [CrossRef]

15. Patacsil, F.F.; Fernandez, M.M.; Cenas, P.V. Exploring the importance of employable skills as perceived by OJT engineering students and industry partners. Int. J. Multidiscip. Acad. Res. 2017, 5, $23-35$.

16. Marrelli, A.E.; Tondora, J.; Hoge, M.A. Strategies for developing competency models. Adm. Policy Ment. Health 2005, 32, 533-561. [CrossRef] [PubMed]

17. Gayeski, D.M.; Golden, T.P.; Andrade, S.; Mason, H. Bringing competency analysis into the 21st century. Perform. Improv. 2007, 46, 9-16. [CrossRef]

18. Nworie, J. Using the Delphi technique in educational technology research. Techtrends Link. Res. Pract. Improv. Learn. 2011, 55, 24-30. [CrossRef]

19. Wu, Y.L. Delphi technique and it's application in curriculum study. J. Educ. Res. 2001, 9, 297-306.

20. Delbecq, A.L. Group Techniques for Program Planning: A Guide to Nominal Group and Delphi Processes; Scott, Foresman and Company: Upper Saddle River, NJ, USA, 1975.

21. Martilla, J.A.; James, J.C. Importance performance analysis. J. Mark. 1977, 41, 77-79. [CrossRef]

22. Gay, L.R. Educational Research Competencies for Analysis and Application; Macmillan: New York, NY, USA; Prentice Hall: Hoboken, NJ, USA, 1992.

23. Antonio, A.A.; Benitez, M.; Castro, J.L. Consistency measures for feature selection. J. Intell. Inf. Syst. 2008, 30, $273-292$.

24. Simpson, O. Student Retention in Online, Open and Distance Learning; Kogan: London, UK, 2003.

25. Johnson, R.B.; Onwuegbuzie, A.J. Mixed method research: A research paradigm whose time has come. Educ. Res. 2004, 33, 14-26. [CrossRef]

26. Klein, J.D.; Spector, J.M.; Grabowski, B.; Teja, I. Instructor Competencies: Standards for Face-to-Face, Online and Blended Settings, 3rd ed.; Information Age Publishing: Greenwich, CT, USA, 2004. 